\title{
Effects of Temperature and Humidity on Fungal Occurrence in Dried Red Pepper during Storage
}

\author{
*Corresponding author \\ Tel: +82-63-238-3401 \\ Fax: $+82-63-238-3840$ \\ E-mail: tessyl@korea.kr \\ ORCID \\ https://orcid.org/0000-0002-8230-650X
}

\author{
Sosoo Kim ', Seul Gi Baek', Nguyen Bao Hung ${ }^{2}$, Se-Ri Kim ${ }^{1}$, Ja Yeong Jang', \\ Jeomsoon Kim ${ }^{1}$, and Theresa Lee ${ }^{1 *(D)}$ \\ 'Microbial Safety Division, National Institute of Agricultural Sciences, Wanju 55365, Korea \\ ${ }^{2}$ Laboratory of Enzyme and Protein Technology, Institute of Biotechnology, Hue University, Hue 530000, \\ Vietnam
}

Received October 29, 2021

Revised December 17, 2021

Accepted December 17, 2021
Dried red peppers are frequently contaminated with mycotoxins during storage. To determine the effect of storage environments on fungal occurrence and subsequent mycotoxin accumulation in dried red peppers, we monitored red pepper powder and whole fruit samples for fungal occurrence under various temperatures and relative humidity $(\mathrm{RH})$ conditions during 340 days. Fungal occurrences fluctuated in both pepper forms throughout the storage but they were higher in pepper powder than whole one, higher under low temperatures $\left(-20^{\circ} \mathrm{C}, 0^{\circ} \mathrm{C}\right.$, or $\left.4^{\circ} \mathrm{C}\right)$ than others $\left(10^{\circ} \mathrm{C}, 25^{\circ} \mathrm{C}\right.$, or $\left.30^{\circ} \mathrm{C}\right)$, and higher under $\mathrm{RH} 93 \%$ than $\mathrm{RH} 51 \%$ and $69 \%$ in both peppers. The samples exhibiting high fungal occurrences were associated mainly with dominant species such as Aspergillus sydowii, Penicillium solitum, P. roqueforti, P. polonicum, or P. chrysogenum. Mycotoxigenic species, including A. flavus, A. ochraceus, A. westerdijkiae, A. tubingensis, and $P$. citrinum, were also detected throughout the samples. Although mycotoxins were not detected in the samples, mycotoxigenic potential of $A$. flavus, $A$. ochraceus, and $A$. westerdijkiae isolates were confirmed. These results show that low temperatures $\left(-20^{\circ} \mathrm{C}, 0^{\circ} \mathrm{C}\right.$, or $\left.4^{\circ} \mathrm{C}\right)$ and/or high surrounding $\mathrm{RH}(>93 \%)$ are not safe environments for storage of dried red peppers as fungal growth can occur under these conditions.

Keywords: Dried red pepper, Fungi, Mycotoxin, Relative humidity, Temperature

\section{Introduction}

Dried red peppers are among the most commonly used spices worldwide. More than $60 \%$ of the global dried red pepper supply is produced in Asian countries, including India, China, Bangladesh, and Thailand (Kim, 2014). The critical control points in this process are the drying of fresh red pepper and storage of dried pepper (Özkan et al., 2015). Whole dried red peppers are processed further to produce various ground products (e.g., red pepper powder, chili powder, and

Research in Plant Disease

pISSN 1598-2262, elSSN 2233-9191

www.online-rpd.org chili pepper flakes), which are distributed widely in markets.

Mycotoxin contamination is an important safety issue associated with dried red peppers. Although dried spices are generally expected to remain intact for long periods, mycotoxin contamination has often been reported in various countries. Aflatoxins (AFs) are the most frequently detected mycotoxins in dried red peppers (Ali et al., 2015; Aydin et al., 2007; Fazekas et al., 2005; Khan et al., 2014; Özkan et al., 2015; Singh and Cotty, 2017). Co-occurrence of AFs and ochratoxin A (OTA) has also been reported (Jegal et al., 2013; Kim et al., 2009; Ozbey and Kabak, 2012; Salari et al., 2012; Santos et al., 2010). Due to the high toxicity of AFs and OTA, these mycotoxins must be regulated to ensure food safety. Recently, the Codex Committee on Contaminants in Foods (CCCF) has started to set maximum levels for AFs and OTA in spices, 
including red pepper (CCCF, 2018). As mycotoxins are fungal metabolites, yeast and mold counts are generally used to indicate the level of microbiological risk in foods. Among yeasts and molds, the most frequent contaminants associated with pepper products are Aspergillus and Penicillium spp. (Adebanjo and Shopeju, 1993; Costa et al., 2019; Ham et al., 2016; Santos et al., 2011), including many important mycotoxigenic species such as A. flavus (Ham et al., 2016; Mandeel, 2005).

Dried pepper products generally take several months from production to consumption, hence, it is important to avoid the microbial contamination during storage. Many studies have documented microbial increases and physicochemical changes in dried red pepper after long-term storage (Choi et al., 2018; Duman, 2010; Kim et al., 1984; Park et al., 1994; Rico et al., 2010). Previous works mainly targeted red pepper powders rather than whole dried red peppers, which are usually stored as raw materials to make a red pepper powder or often directly used in cooking. In present study, we investigated fungal occurrence on red pepper powder and whole dried red pepper under different storage conditions (temperature and relative humidity $[\mathrm{RH}]$ ) during long-term monitoring (about 1 year).

\section{Materials and Methods}

Sampling and storage conditions. We purchased red pepper powder and whole dried red pepper from two manufacturers located in Chungnam and Gyeongbuk provinces, respectively, which are about $240 \mathrm{~km}$ apart from each other in Korea. The samples were labeled $A$ and $B$ by regions (Chungnam and Gyeongbuk provinces, respectively). Whole dried peppers were bought in bulk and subdivided into 250 $\mathrm{g}$ in low density polyethylene double zipper bags for the experiments. Pepper powders came as individually packaged in a single 1-kg vinyl zipper bag and they were used for storage without further division.

Pepper powders and dried whole peppers were stored under a range of temperature and $\mathrm{RH}$ conditions. All samples were stored at different temperatures of $-20^{\circ} \mathrm{C}, 0^{\circ} \mathrm{C}$, $4^{\circ} \mathrm{C}, 10^{\circ} \mathrm{C}, 25^{\circ} \mathrm{C}$, and $30^{\circ} \mathrm{C}$, except for dried peppers. Dried peppers were not stored at $-20^{\circ} \mathrm{C}$ because they are usually stored at around $0^{\circ} \mathrm{C}$. Saturated aqueous solutions of $\mathrm{Mg}\left(\mathrm{NO}_{3}\right)_{2}, \mathrm{Kl}$, and $\mathrm{KNO}_{3}$ were prepared to attain $51 \%, 69 \%$, and $93 \% \mathrm{RH}$, respectively as previously described (Greenspan, 1977), in individual airtight polypropylene plastic containers
$(29.0 \times 19.5 \times 15.5 \mathrm{~cm})$. For saturated salt solutions, each salt was dissolved in warm distilled water with stirring until no more excess salt dissolved. For each type of pepper, pairs of samples (A and B) in separate plastic bags were placed in stack in incubators set at different temperatures or up on the rack to avoid direct contact with the solution in separate containers for $\mathrm{RH}$ treatment. The $\mathrm{RH}$ containers were placed in a room maintained at $25 \pm 2^{\circ} \mathrm{C}$ for the entire study period and kept airtight to ensure its $\mathrm{RH}$ during storage. Storage started right after the sample arrival and the initial status of the samples was measured as 0 day. During the storage, we sampled $7 \mathrm{~g}$ whole pepper and $20 \mathrm{~g}$ pepper powder from each treatment every 10 days for fungal and mycotoxin analyses, until the amount of pepper remaining in the treatments was insufficient for sampling. The moisture content (MC) of each sample was measured upon collection using a moisture analyzer (HMM-700E, Han Young Systems, Seoul, Korea). Every 30 days starting at 10 days, the water activity of the samples was measured using a water activity meter (LabMaster-aW, Novasina, Lachen, Switzerland).

Fungal occurrence and identification. To investigate fungal occurrence in the samples, we prepared the samples as reported previously (Ham et al., 2016). Each mixture (1 $\mathrm{g}$ of pepper powder sample with $9 \mathrm{ml}$ sterile water) was vortexed vigorously for $1 \mathrm{~min} ; 2 \mathrm{ml}$ of this mixture was then spread onto potato dextrose agar (PDA; Difco, Detroit, MI, USA) plates (200 $\mu \mathrm{l}$ mixture per plate). Fungal colonies were counted after 5 days of incubation at $25^{\circ} \mathrm{C}$. Whole pepper samples were cut into $5 \times 5$-mm squares, and 50 random cuts were placed on PDA plates. Incubation and colony counts were performed as described above. Fungal occurrence was calculated as the number of colony-forming units (cfu) per gram of sample after averaging weighs of 50 counts.

Fungal colonies were identified visually at first based on colony and spore morphology for Aspergillus and Penicillium counting. Then, representative colonies were isolated and all the isolates were subjected to PCRs to identify species using ITS4/5, $\beta$-tubulin, or calmodulin genes. To screen for mycotoxin producibility PCRs were performed using norB-cypA gene for AFs and ketosynthase domain of polyketide synthase gene for OTA. All PCRs were carried out as described previously (Ham et al., 2016).

Mycotoxin analysis. Selected samples were analyzed 
for AFs $B_{1}, B_{2}, G_{1}, G_{2}$, and OTA. We extracted $4 \mathrm{~g}$ of each sample with $70 \%$ methanol (with $1 \% \mathrm{NaCl}$ ) for AFs. The extracts were cleaned using immuno-affinity columns (AflaTest WB, VICAM, Milford, MA, USA), according to the manufacturer's instructions. The samples were dried under nitrogen gas, reconstituted in $1 \mathrm{~mL}$ acetonitrile solution with $20 \%$ trifluoroacetic acid, and then filtered $(0.22 \mu \mathrm{m}$, SiliCycle, Quebec, Canada) before injection into an ultra-high-performance liquid chromatography (UPLC) system (ACQUITY UPLC HClass, Waters, Singapore). We injected $10 \mu$ of each sample into a reverse-phase $\mathrm{C} 18$ column (X-Select CSH C18; $2.5 \mu \mathrm{m}$, $2.1 \times 100 \mathrm{~mm}$; Waters, Dublin, Ireland). The mobile phase consisted of water-methanol-acetonitrile (76:14:10, v/v/v) was run isocratically at a flow rate of $0.3 \mathrm{ml} / \mathrm{min}$. For OTA, $1 \mathrm{~g}$ of each sample was extracted with methanol-sodium bicarbonate (50:50) solution and cleaned with an OchraTest WB (VICAM) immune-affinity column. The samples were dried as described above, reconstituted with acetonitrile-wateracetic acid (99:99:2), and analyzed by UPLC with the same solution as a mobile phase. The limit of quantification for AFs and OTA was $0.5 \mu \mathrm{g} / \mathrm{kg}$. These analyses were repeated three times.

\section{Results}

Effect of temperature on fungal occurrence. Fungal occurrence fluctuated, with occasional sharp increases, throughout the storage period in both whole and pepper powder samples. The fungal occurrences appeared to be higher at low temperatures (from $-20^{\circ} \mathrm{C}$ to $4^{\circ} \mathrm{C}$ ) and especially in pepper powder samples, usually orders of magnitude higher than those in whole. Analysis of data collected every 30 days showed that the median fungal occurrences through the storage period is the highest in the pepper powder $\mathrm{A}$ at $-20^{\circ} \mathrm{C}\left(8.3 \times 10^{2} \mathrm{cfu} / \mathrm{g}\right)$, followed by $0^{\circ} \mathrm{C}\left(4.1 \times 10^{2}\right)$, $4^{\circ} \mathrm{C}\left(3.3 \times 10^{2}\right)$, and $4^{\circ} \mathrm{C}\left(1.4 \times 10^{2}\right)$ in the pepper powder B (Fig. 1). In whole peppers, fungal occurrences only at $4^{\circ} \mathrm{C}$ were higher than other temperatures in both samples (Fig. 1). The highest fungal occurrence $\left(2.5 \times 10^{4} \mathrm{cfu} / \mathrm{g}\right.$ at 180 days) was observed in pepper powder sample $\mathrm{B}$ at $4^{\circ} \mathrm{C}$ (Fig. 2). Other high occurrences were observed in pepper powder sample A at $0^{\circ} \mathrm{C}\left(8.1 \times 10^{3}\right.$ at 260 days $)$ and at $-20^{\circ} \mathrm{C}\left(2.6 \times 10^{3} \mathrm{cfu} / \mathrm{g}\right.$ at 200 days) (Supplementary Table 1). At these temperatures, fungal occurrence fluctuated during the whole period, which pattern was a contrast to the higher temperatures. Relatively higher temperature treatments $\left(10^{\circ} \mathrm{C}, 25^{\circ} \mathrm{C}\right.$, and

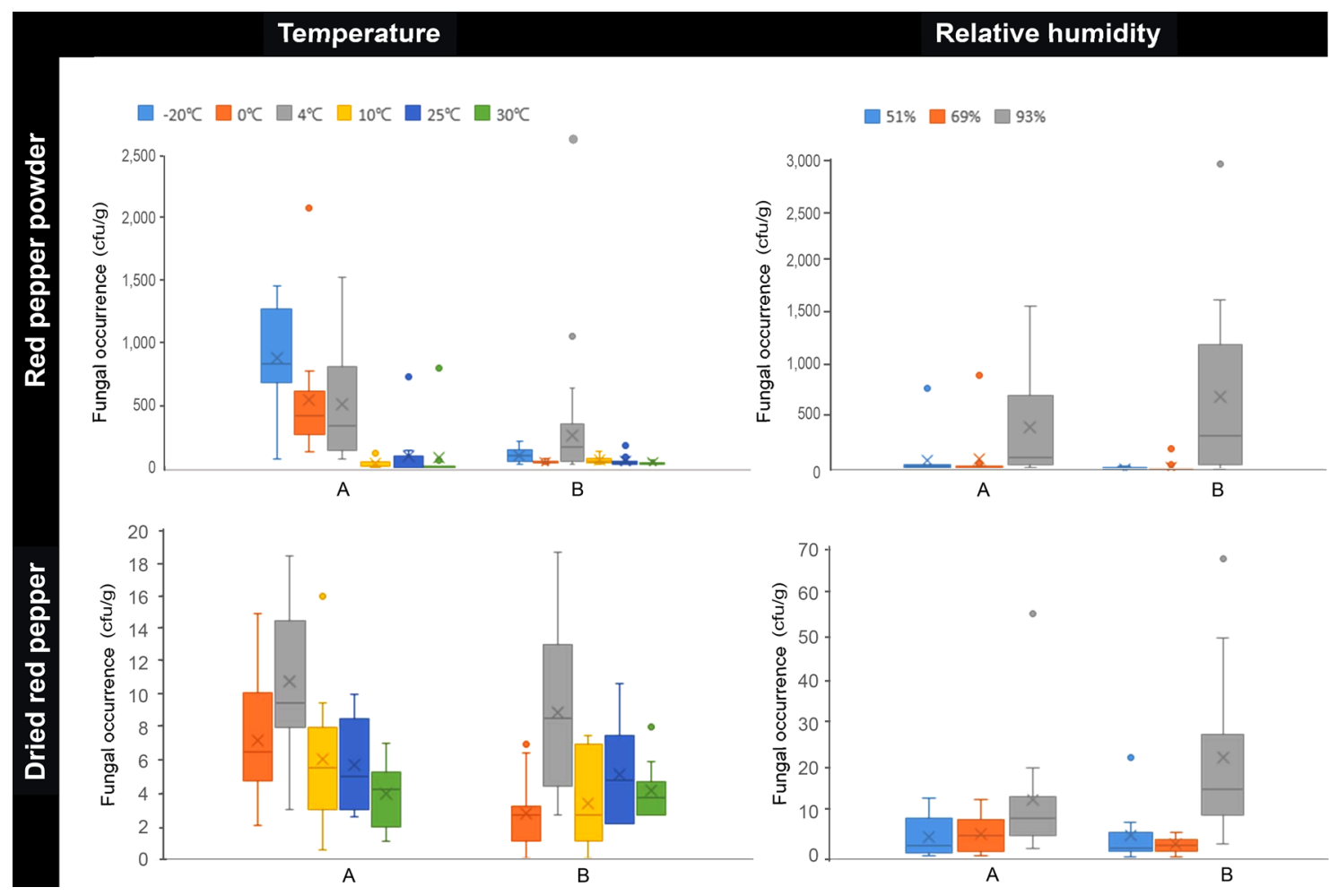

Fig. 1. The effect of temperature and humidity on fungal occurrence on red pepper powder and dried red pepper samples. Peppers were purchased from two different manufacturers located in Chungnam and Gyeongbuk provinces ( $A$ and B). 
$30^{\circ} \mathrm{C}$ ) showed flat and lower occurrence during the entire storage. For whole peppers, the highest peaks occurred at $4^{\circ} \mathrm{C}$ (70 days) for both samples $A$ and $B$ but with very low occurrences (Fig. 1, Supplementary Fig. 1).

The dominant fungal genera associated with dried pepper varied among samples and conditions. Pepper powder A was associated mainly with Penicillium, especially at $-20^{\circ} \mathrm{C}$ and $0^{\circ} \mathrm{C}$, whereas pepper powder $\mathrm{B}$ was associated with $A s-$ pergillus at $-20^{\circ} \mathrm{C}, 0^{\circ} \mathrm{C}$, and $4^{\circ} \mathrm{C}$ (Supplementary Table 1). The predominant Penicillium species occurred were $P$. solitum, $P$. roqueforti, P. polonicum, and P. chrysogenum, and the predominant Aspergillus species was A. sydowii. In whole pepper samples, A. sydowii was dominant at all temperatures. Representative mycotoxigenic species, such as A. flavus (AFs), A. ochraceus, and A. westerdijkiae (OTA), were occasionally detected from the samples regardless of storage conditions or period (Supplementary Table 1). A. flavus was detected frequently in pepper powder $\mathrm{B}$, whereas $A$. ochraceus and $A$. westerdijkiae were found in whole $A$. A. tubingensis occurred more frequently in sample $B$ (both whole and powder). None of these species contributed to the fungal occurrence peaks shown in Fig. 2 during the study period. It is notable that in pepper powder B, A. flavus was detected only from cold temperatures lower than $10^{\circ} \mathrm{C}$.

Effect of RH on fungal occurrence. Fungal occurrence appeared to increase with a pattern only at $93 \% \mathrm{RH}$ in both pepper powder and whole pepper samples. Median of fungal occurrence was significantly higher at $93 \%$ than $51 \%$ and $69 \%$ in all the samples of both pepper forms (Fig. 1). In pep-
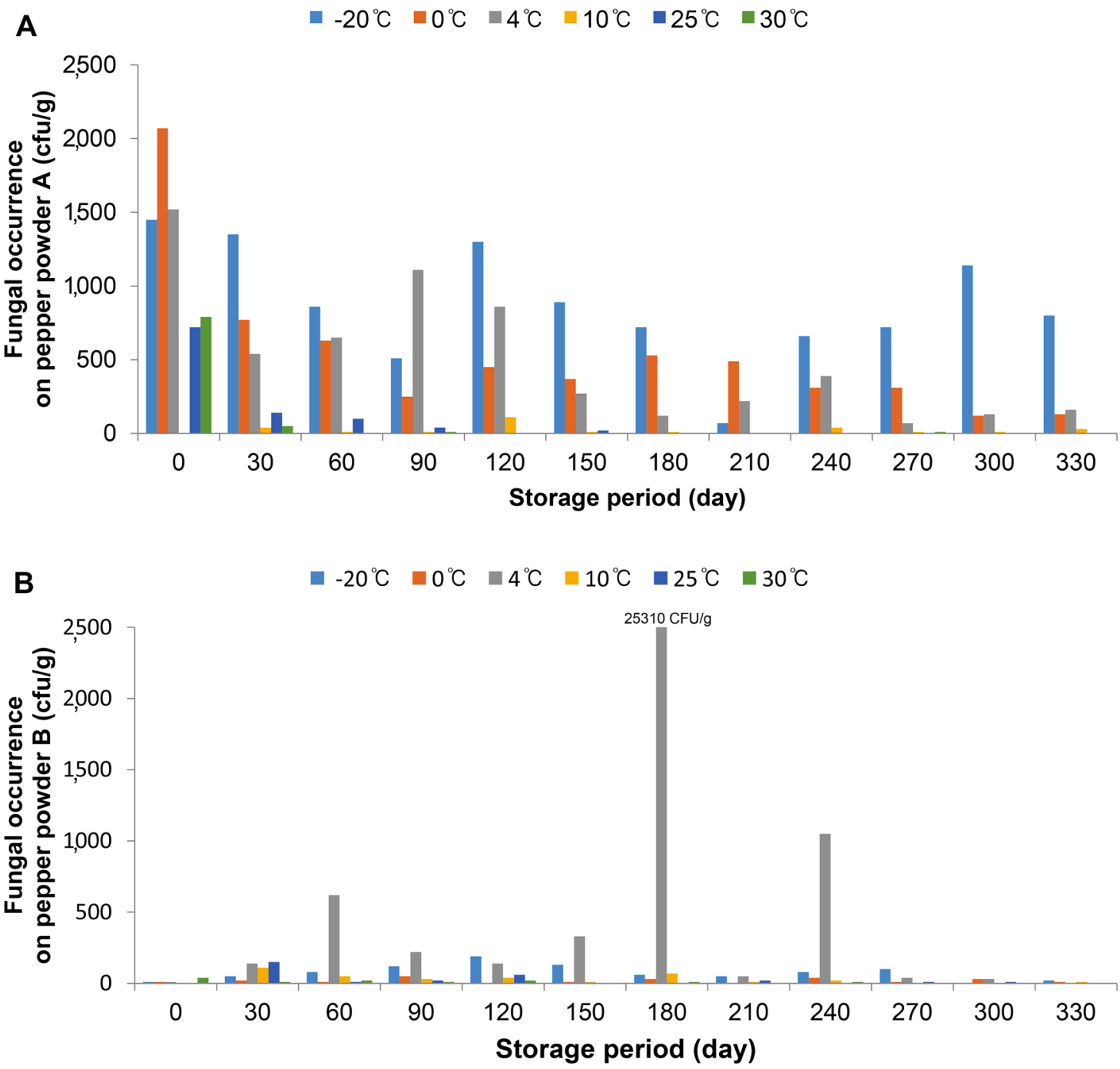

Fig. 2. The effect of temperature on fungal occurrence on pepper powder samples $A(A)$ and $B(B)$. 
A $\quad \square 51 \% \quad 69 \% \quad \square 3 \%$
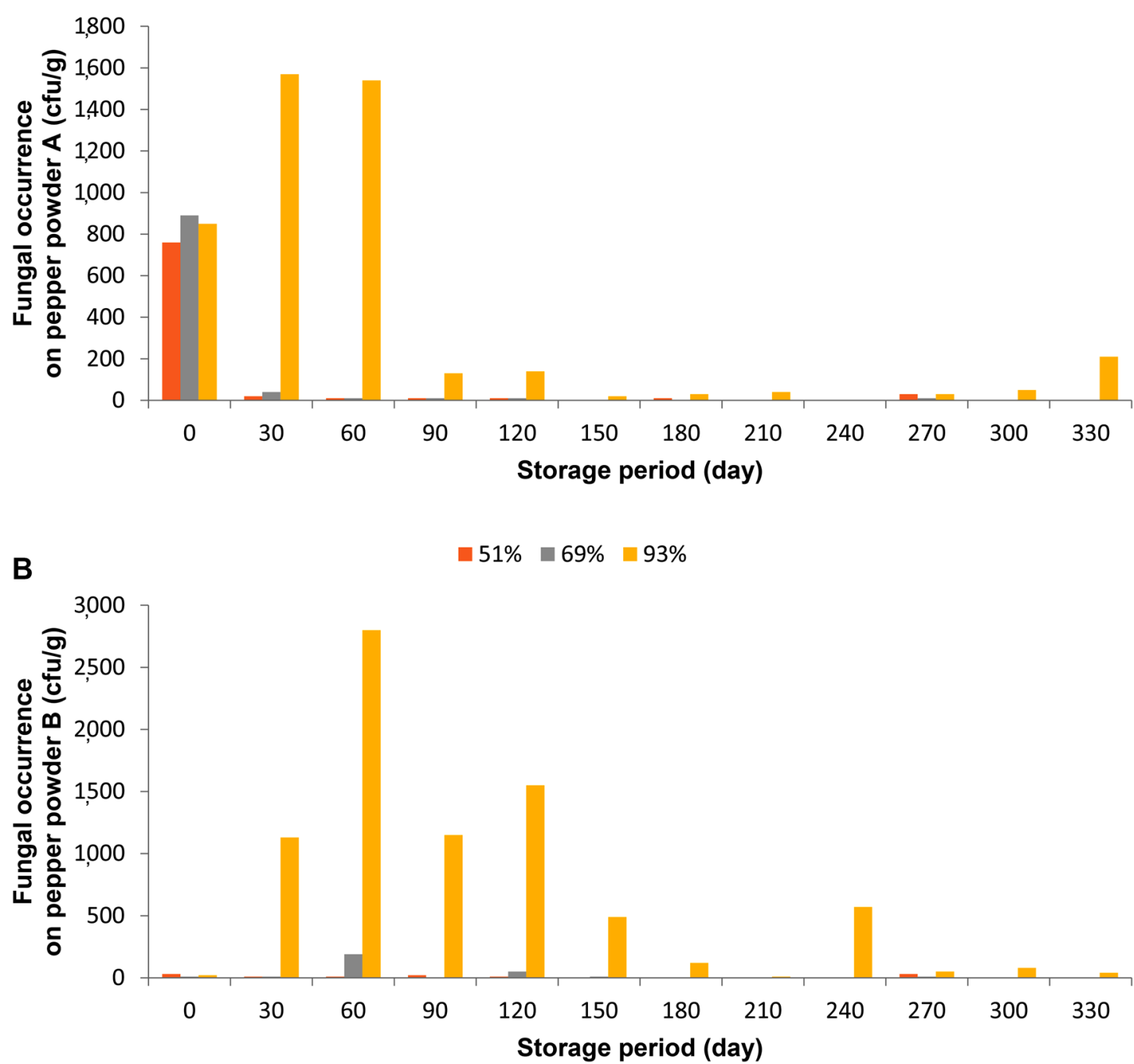

Fig. 3. The effect of relative humidity on fungal occurrence on pepper powder samples $A(A)$ and $B(B)$.

per powders, fungal occurrence tended to increase during early storage then, decrease (Fig. 3). Whole pepper samples showed a slower increase than did pepper powder ones, resulting in a rightward shift of the fungal occurrence trend (Supplementary Fig. 2). Fungal occurrence in the whole samples were two orders of magnitude lower than those of the pepper powder samples. At $69 \%$ and $51 \%$ RH, no pepper powder samples showed a significant increase in fungal occurrence, which remained lower than $2.0 \times 10^{2} \mathrm{cfu} / \mathrm{g}$ throughout the storage period, except the sample $B$ at day 10 under $69 \%$ RH (Supplementary Table 1). The fungal occurrence of whole pepper samples fluctuated below $2.2 \times 10 \mathrm{cfu} / \mathrm{g}$. Most samples were associated with $A$. sydowii, especially at $93 \%$ $\mathrm{RH}$, throughout the storage periods and with mycotoxigenic species such as $A$. flavus, A. ochraceus, $A$. westdijkiae, and $A$. tubingensis at all RH levels (Supplementary Table 1).

MC and water activity of pepper samples. The MC and water activity of the samples varied with temperature, $\mathrm{RH}$, and pepper form throughout the storage period. $\mathrm{MC}$ decreased gradually in the pepper powder samples under the $30^{\circ} \mathrm{C}$ treatment after 120 days, but changed little at other temperatures (<14\%) (Supplementary Fig. 3). In whole pepper, $\mathrm{MC}$ declined with fluctuation at $10^{\circ} \mathrm{C}$ and higher temperatures, most steeply under the $30^{\circ} \mathrm{C}$ treatment, where it was not detectable after 130 days. Under the $0^{\circ} \mathrm{C}$ and $4^{\circ} \mathrm{C}$ treatments, MC of whole pepper fluctuated but remained around at $12 \pm 1-2 \%$. Water activity of both pepper powder 
Table 1. Mycotoxigenic potential of selected fungal isolates

\begin{tabular}{lccc}
\hline \multicolumn{1}{c}{ Species } & No. of isolate & Aflatoxin & Ochratoxin \\
\hline Aspergillus flavus & $16^{\mathrm{a}}$ & 1 & $\mathrm{nt}$ \\
A. nomius & 5 & 2 & $\mathrm{nt}$ \\
A. oryzae & 5 & 0 & $\mathrm{nt}$ \\
A. ruber & 6 & 0 & $\mathrm{nt}$ \\
A. ochraceus & 6 & $\mathrm{nt}$ & 2 \\
A. tubingensis & 2 & $\mathrm{nt}$ & 0 \\
A. westerdijkiae & 7 & $\mathrm{nt}$ & 4 \\
Penicillium citrinum & 11 & $\mathrm{nt}$ & 1 \\
P. nordicum & 3 & $\mathrm{nt}$ & 0 \\
P. verrucosum & 3 & $\mathrm{nt}$ & 0 \\
Total & 64 & 3 & 7 \\
\hline
\end{tabular}

nt, not tested.

${ }^{\mathrm{a}}$ To screen for ability of mycotoxin production, PCRs were performed using norB-cypA gene for aflatoxin and ketosynthase domain of polyketide synthase gene for ochratoxin. Each species was tested for one mycotoxin only. Number of isolate with an expected band was counted.

and whole samples showed similar trends to the $M C(<0.8)$ (Supplementary Fig. 4). With RH treatment, the MC and water activity of both pepper powder and whole samples increased throughout the test period at 69 and 93\%; the greater $\mathrm{RH}$ resulted in the higher $\mathrm{MC}$ and water activity over time, with acquisition of more moisture in whole pepper samples than pepper powder ones (Supplementary Figs. 3, 4). Occasional upsets observed in Supplementary Fig. 3 could be measuring errors.

Mycotoxin production. We screened the capabilities of the 64 isolates to produce AF and OTA based on the presence of the fungal genes required for the biosynthesis of these mycotoxins. None of them were from the same sample and their origin covered whole range of temperature or $\mathrm{RH}$ as some were marked in Supplementary Table 1. These isolates were identified as one of eight mycotoxigenic species (A. flavus, A. ochraceus, A. ruber, A. tubingensis, A. westerdijkiae, $P$. verrucosum, $P$. citrinum, and $P$. nordicum) that were known to produce either AF or OTA. One A. flavus and two A. nomius isolates were found to be positive for $A F$, and seven (four A. westerdijkiae, two A. ochraceus, and one $P$. citrinum) were found to be positive for OTA (Table 1). However, none of AF and OTA was detected above the quantification limit in any of the ground or whole pepper samples examined in this study (data not shown).

\section{Discussion}

During about 1-year storage, $4^{\circ} \mathrm{C}$ and lower temperatures or high $\mathrm{RH}$ (e.g., 93\%) appeared to encourage fungal growth in both pepper powder and whole dried pepper samples. This finding is contrary to general assumption that cold temperatures generally limit microbial growth. Rather, advantage of cold temperature for pepper would be attributed to maintaining its quality. Regarding to temperature, inconsistent results have been reported for microbial reduction in red pepper powder. One study showed that storage of red pepper powder at room temperature for 6 months caused no change in yeast and mold counts (Lee et al., 1997), whereas another showed that yeast and mold counts decreased by two orders of magnitude, from $4.6 \times 10^{3} \mathrm{cfu} / \mathrm{g}$ to $1.2 \times 10$, after 6 months of storage at $4 \pm 2^{\circ} \mathrm{C}$ (Rico et al., 2010). With 10-day interval measurement, our work revealed fluctuations in fungal contaminant levels, rather than proportional change, notably with peaks at cold temperatures. Why occurrence levels increased at certain time points and were not maintained remains unclear but it could have been caused by sampling, as fungal spores or mycelial mass are unevenly attached to ground particles or inner surfaces of whole peppers without free dispersal. In addition, this study revealed for the first time that whole pepper fruits were less susceptible to fungal occurrence (contamination) than pepper powder samples at all the time points examined. Previous studies can be comparable to our result as they documented greater AF contamination of ground pepper than of whole peppers (Khan et al., 2014; Kim et al., 2005; Singh and Cotty, 2017). In this regard, it can be speculated that the ground samples provide more surface areas for fungal colonization than whole fruit samples, suggesting that whole pepper is more suitable form than pepper powder for long-term storage in terms of microbial reduction only when the environments are controlled properly.

As fungal occurrence was inconsistent with $\mathrm{MC}$ or water activity which showed increasing/decreasing pattern respective to temperature, it might be due to some change in the pepper microenvironments rather than water content in the peppers. However, further investigation is required as we did 
not measure $\mathrm{RH}$ among the temperature treatments and there could be other factors such as packaging material and air-flow. We did not measure the qualitative indices of the stored samples but the color started to deteriorate visually at $30^{\circ} \mathrm{C}$ (from 120 days) and at $25^{\circ} \mathrm{C}$ (from 230 days) in the whole pepper.

$\mathrm{RH}$ accelerated fungal growth in both pepper powder and whole pepper samples only at a high level (93\%). Fungal occurrence showed a pattern looking like an inverted v-shaped curve with a peak at 50 days for ground samples, and later for whole ones (Supplementary Table 1). The pattern clearly showed that fungal occurrence increased to a certain point where the humidity reached saturation then decreased; increasing humidity encouraged fungal growth. It was irrelevant with either MC or water activity again as in the temperature treatment. As this pattern was common to both pepper forms, it suggests that surrounding high humidity $(93 \% \mathrm{RH})$ was the critical factor to promote fungal growth (of spores or mycelia). The peak time difference between two pepper forms may reflect the physical structures of them, with more time required for the saturation of whole peppers. It also indicates that the commercial zip bags used in the study were not airtight enough to block penetration of surrounding airs completely. Although dried red pepper was not usually stored under such high $\mathrm{RH}$, humidity can be increased without proper control. A previous study on the quality of stored dried red pepper showed that the optimal storage conditions were $13-15 \%$ water content and $60 \% \pm 5 \%$ RH (Park et al., 1994). Red pepper powder has also been reported to brown at high-equilibrium MC and $\mathrm{RH}$ higher than $75 \%$ (Kim et al., 1984). Regarding to mycotoxin production, high levels of water activity ( $>0.9$ ) have been reported to favor OTA production by Aspergillus section Nigri (Bellí et al., 2004). However, the water activity levels of dried red pepper tested in this study were lower than 0.8; thus, this effect was not observed. Another study showed that $A$. flavus was able to grow and produce AFs at $21^{\circ} \mathrm{C} / 97 \% \mathrm{RH}$ and $30^{\circ} \mathrm{C} / 85 \% \mathrm{RH}$ in rice (Choi et al., 2015). In rice, Aspergillus populations were affected more by temperature $\left(>10^{\circ} \mathrm{C}\right)$ than by $\mathrm{RH}$ (Mannaa and Kim, 2018).

Most peaks of fungal occurrence levels during storage consisted of single species of the genera Aspergillus or Penicillium. Associations with single dominant species varied among samples and treatments. A. sydowii was dominant in both pepper types at $93 \% \mathrm{RH}$, indicating that $A$. sydowii was best suited to the high RH (Supplementary Table 1). Although these dominant species are known to be nontoxigenic (Frisvad et al., 2004; Pitt and Hocking, 2009), other Aspergillus and Penicillium species detected are producers of various toxic metabolites (Frisvad et al., 2004; Ismaiel and Papenbrock, 2015; Nielsen et al., 2009; Wang et al., 2016). The co-occurrence of many mycotoxigenic species, such as $A$. flavus, A. ochraceus, A. westerdijkiae, A. tubingensis, P. verrucosoum, and $P$. citrinum, can still pose a threat to food safety. $P$. citrinum can produce citrinin (Jeswal and Kumar, 2015) and OTA (Zhao et al., 2017). We did not analyze our samples for citrinin, but we found that one $P$. citrinum isolate had the potential for OTA production. A. tubingensis that was detected commonly in our samples belongs to Aspergillus section Nigri with $A$. niger and $A$. carbonarius. A. niger has been found in frequent association with red pepper (Bokhari, 2007; Erdogan, 2004). A. tubingensis from grapes has been reported to produce OTA but with frequencies lower than $A$. niger and A. carbonarius (Perrone et al., 2006); thus, whether A. tubingensis isolates from red pepper also produce OTA must be determined. Chilies have been suspected to contain quantities of Aspergillus section Flavi (Singh and Cotty, 2017). As we confirmed its presence in our samples and aflatoxigenic or ochratoxigenic potential by a few isolates, the production of AFs and OTA will depend on storage conditions. A couple of studies reported such cases: AF levels increase after 5-month storage of hot pepper, with $61 \%$ greater contamination at $25^{\circ} \mathrm{C}$ and $30^{\circ} \mathrm{C}$ than at $20^{\circ} \mathrm{C}$ (lqbal et al., 2011); a 10-fold increase in yeast and mold counts with the $A F B_{1}$ increasing from $<0.2$ to $1.56 \mu \mathrm{g} / \mathrm{kg}$ after 6 -month storage of red chili pepper (Duman, 2010). No detection of mycotoxins in our samples might be due to lack of the conducive condition or fungal quantity for mycotoxin production during storage. As long as the mycotoxigenic strains survive, however, mycotoxin can be produced when the condition becomes suitable and the fungi proliferate.

This study provides a glimpse of unexpected fungal population dynamics in dried red pepper during storage. It shows that cold temperatures can promote fungal growth. It is important to know that cold storage such as $-20^{\circ} \mathrm{C}$ does not guarantee to control fungal contamination but can harbor fungi including mycotoxigenic species. As pepper powders hold more fungi than whole fruit ones, whole pepper is a safer form for long-term storage than ground one to reduce fungal occurrence. Although fungal increase was not related 
with either $M C(<16 \%)$ or water activity $(<0.8)$ of the samples in both forms of pepper, high $\mathrm{RH}$ needs to be controlled to minimize fungal propagation in dried red pepper storage.

\section{Conflicts of Interest}

No potential conflict of interest relevant to this article was reported.

\section{Acknowledgments}

This work was supported by the National Institute of Agricultural Sciences, Rural Development Administration, Republic of Korea (Project No. PJ012676).

\section{Electronic Supplementary Material}

Supplementary materials are available at Research in Plant Disease website (http://www.online-rpd.org/).

\section{References}

Adebanjo, A. and Shopeju, E. 1993. Sources and mycoflora associated with some sundried vegetables in storage. Int. Biodeterior. Biodegrad. 31: 255-263.

Ali, N., Hashim, N. H. and Shuib, N. S. 2015. Natural occurrence of aflatoxins and ochratoxin $A$ in processed spices marketed in Malaysia. Food Addit. Contam. Part A Chem. Anal. Control Expo Risk Assess. 32: 518-532.

Aydin, A., Erkan, M. E., Başkaya, R. and Ciftcioglu, G. 2007. Determination of aflatoxin $B_{1}$ levels in powdered red pepper. Food Control 18: 1015-1018.

Bellí, N., Ramos, A. J., Sanchis, V. and Marin, S. 2004. Incubation time and water activity effects on ochratoxin A production by Aspergillus section Nigri strains isolated from grapes. Lett. Appl. Microbiol. 38: 72-77.

Bokhari, F. M. 2007. Spices mycobiota and mycotoxins available in Saudi Arabia and their abilities to inhibit growth of some toxigenic fungi. Mycobiology 35: 47-53.

Choi, S., Jun, H., Bang, J., Chung, S.-H., Kim, Y., Kim, B.-S. et al. 2015. Behaviour of Aspergillus flavus and Fusarium graminearum on rice as affected by degree of milling, temperature, and relative humidity during storage. Food Microbiol. 46: 307-313.

Choi, J. I., Oh, H. I., Cho, M. S. and Oh, J. E. 2018. Change in the quality characteristics of red pepper powder according to the storage method. J. Korean Soc. Food Cult. 33: 125-132. (In Korean)

Codex Committee on Contaminants in Foods (CCCF). 2018. Report of CCCF12. URL http://www.fao.org/fao-who-codexalimentar-
ius/meetings/detail/en/?meeting=CCCF\&session=14 [23 July 2021].

Costa, J., Rodríguez, R., Garcia-Cela, E., Medina, A., Magan, N., Lima, N. et al. 2019. Overview of fungi and mycotoxin contamination in Capsicum pepper and in its derivatives. Toxins 11:27.

Duman, A. D. 2010. Storage of red chili pepper under hermetically sealed or vacuum conditions for preservation of its quality and prevention of mycotoxin occurrence. J. Stored Prod. Res. 46: 155160.

Erdogan, A. 2004. The aflatoxiin contamination of some pepper types sold in Turkey. Chemosphere 56: 321-325.

Fazekas, B., Tar, A. and Kovács, M. 2005. Aflatoxin and ochratoxin A content of spices in Hungary. Food Addit. Contam. 22: 856-863.

Frisvad, J. C., Smedsgaard, J., Larsen, T. O. and Samson, R. A. 2004. Mycotoxins, drugs and other extrolites produced by species in Penicillium subgenus Penicillium. Stud. Mycol. 49: 201-241.

Greenspan, L. 1977. Humidity fixed points of binary saturated aqueous solutions. J. Res. Natl. Bur. Stand. A Phys. Chem. 81 A: 8996.

Ham, H., Kim, S., Kim, M.-H., Lee, S., Hong, S. K., Ryu, J.-G. et al. 2016. Mycobiota of ground red pepper and their aflatoxigenic potential. J. Microbiol. 54: 832-837.

lqbal, Q., Amjad, M., Asi, M. R. and Ariño, A. 2011. Assessment of hot peppers for aflatoxin and mold proliferation during storage. J. Food Prot. 74: 830-835.

Ismaiel, A. A. and Papenbrock, J. 2015. Mycotoxins: producing fungi and mechanisms of phytotoxicity. Agriculture 5: 492-537.

Jegal, S., Kim, J.-H., Joo, G.-S., Jung, S.-J., Na, H.-J., Jo, N.-G. et al. 2013. Survey of aflatoxin $B_{1}$ and ochratoxin $A$ on commercial dried red pepper and red pepper powder. J. Food Hyg. Saf. 28: 267271. (In Korean)

Jeswal, P. and Kumar, D. 2015. Mycobiota and natural incidence of aflatoxins, ochratoxin A, and citrinin in Indian spices confirmed by LC-MS/MS. Int. J. Microbiol. 2015: 242486.

Khan, M. A., Asghar, M. A., Iqbal, J., Ahmed, A. and Shamsuddin, Z. A. 2014. Aflatoxins contamination and prevention in red chillies (Capsicum annuum L.) in Pakistan. Food Addit. Contam. Part B Surveill. 7: 1-6.

Kim, B.-K., Kausar, T., Kim, D.-H. and Kwon, J.-H. 2005. Effects of gamma-irradiation and fumigation on microbial growth, color and absorption properties of dried red pepper during storage. Korean J. Food Preserv. 12: 48-53. (In Korean)

Kim, D., Jang, H., Kim, Y. and Ahn, J. 2009. Survey for contamination and study for reduction of ochratoxin $A$ and aflatoxin in red pepper. J. Food Hyg. Saf. 24: 299-306.

Kim, H. K., Park, M. H., Min, B. Y. and Suh, K. B. 1984. Sorption characteristics of red pepper powder with relative humidity and temperature. Korean J. Food Sci. Technol. 16: 108-112.

Kim, S. H. 2014. World trend of dried red pepper industry. World Agric. 166: 73-92. (In Korean)

Lee, S.-H., Lee, H.-J. and Byun, M.-W. 1997. Effects of ozone treatment and gamma irradiation on the microbial decontamina- 
tion and physicochemical properties of red pepper powder. J. Korean Soc. Food Sci. Nutr. 26: 462-467.

Mandeel, Q. A. 2005. Fungal contamination of some imported spices. Mycopathologia 159: 291-298.

Mannaa, M. and Kim, K. D. 2018. Effect of temperature and relative humidity on growth of Aspergillus and Penicillium spp. and biocontrol activity of Pseudomonas protegens AS15 against aflatoxigenic Aspergillus flavus in stored rice grains. Mycobiology 46: 287-295.

Nielsen, K. F., Mogensen, J. M., Johansen, M., Larsen, T. O. and Frisvad, J. C. 2009. Review of secondary metabolites and mycotoxins from the Aspergillus niger group. Anal. Bioanal. Chem. 395: 1225-1242.

Ozbey, F. and Kabak, B. 2012. Natural co-occurrence of aflatoxins and ochratoxin A in spices. Food Control 28: 354-361.

Özkan, A., Bindak, R. and Erkmen, O. 2015. Aflatoxin B 1 and aflatoxins in ground red chilli pepper after drying. Food Addit. Contam. Part B Surveill. 8: 227-233.

Park, M.-H., Kim, H.-K. and Kim, G.-H. 1994. A study on quality maintaining of dried red pepper fruits. Korean J. Post-harvest Sci. Technol. Agric. Prod. 1: 81-86.

Perrone, G., Mulè, G., Susca, A., Battilani, P., Pietri, A. and Logrieco, A. 2006. Ochratoxin A production and amplified fragment length polymorphism analysis of Aspergillus carbonarius, Aspergillus tubingensis, and Aspergillus niger strains isolated from grapes in Italy. Appl. Environ. Microbiol. 72: 680-685.

Pitt, J. I. and Hocking, A. D. 2009. Fungi and Food Spoilage. Springer, Boston, MA, USA. 520 pp.
Rico, C. W., Kim, G.-R., Ahm, J.-J., Kim, H.-K., Furuta, M. and Kwon, J.H. 2010. The comparative effect of steaming and irradiation on the physicochemical and microbiological properties of dried red pepper (Capsicum annum L.). Food Chem. 119: 1012-1016.

Salari, R., Habibi Najafi, M. B., Boroushaki, M. T., Mortazavi, S. A. and Fathi Najafi, M. 2012. Assessment of the microbiological quality and mycotoxin contamination of Iranian red pepper spice. J. Agric. Sci. Technol. 14: 1511-1521.

Santos, L., Marín, S., Mateo, E. M., Gil-Serna, J., Valle-Algarra, F. M., Patiño, B. et al. 2011. Mycobiota and co-occurrence of mycotoxins in Capsicum powder. Int. J. Food Microbiol. 151: 270-276.

Santos, L., Marín, S., Sanchis, V. and Ramos, A. J. 2010. Co-occurrence of aflatoxins, ochratoxin $A$ and zearalenone in Capsicum powder samples available on the Spanish market. Food Chem. 122: 826-830.

Singh, P. and Cotty, P. J. 2017. Aflatoxin contamination of dried red chilies: contrasts between the United States and Nigeria, two markets differing in regulation enforcement. Food Control 80: 374-379.

Wang, Y., Wang, L., Liu, F., Wang, Q., Selvaraj, J. N., Xing, F. et al. 2016. Ochratoxin A producing fungi, biosynthetic pathway and regulatory mechanisms. Toxins 8: 83.

Zhao, L., Peng, Y., Zhang, X., Li, J., Zheng, X., Yang, O. et al. 2017. Integration of transcriptome and proteome data reveals ochratoxin A biosynthesis regulated by $\mathrm{pH}$ in Penicillium citrinum. RSC Adv. 7: 46767-46777. 